\title{
SIMON WIGLEY
}

\section{DISAPPEARING WITHOUT A MORAL TRACE? RIGHTS AND COMPENSATION DURING TIMES OF EMERGENCY*}

(Accepted 11 March 2009)

\begin{abstract}
Scholars are divided over whether a victim's rights persist when an agent permissibly responds to an emergency. According to the prevailing view the moral force of rights is not extinguished by moral permissibility and the agent, therefore, has a duty to compensate the victim. According to another influential view permissibility does erase the moral force of rights and the agent, therefore, can only have a duty to compensate for reasons other than the fact that they committed a rights transgression. I argue that liability does not follow even if we grant that the victim's rights persevere. A non-pecuniary remedy such as a formal apology provides an adequate way of vindicating the victim's rights and of recognizing the agent's causal role. Thus, the answer to the question of what remedy the permissible transgressor owes the victim does not provide us with an answer to the question of who should bear the burden.
\end{abstract}

Consider those cases in which an individual damages the property of another so as to escape a deadly predicament - the hiker who breaks into a cabin in order to escape from an unexpected and life threatening blizzard, or the ship captain who jettisons cargo during an unexpected and violent storm in order to prevent the ship from sinking, or the diabetic who takes some of her absent friend's insulin in order to avoid lapsing into a coma. While rare in practice an individual's responses to circumstances of peril are often thought to throw

* This article has greatly benefited from the insightful comments of Josh Cowley, Saul Smilansky, Ulrich Steinvorth, Lars Vinx, Bill Wringe and two anonymous referees. 
into sharp relief a number of key issues in moral and legal philosophy. These include the extent to which rights are a constraint on action, whether a permissible act can also entail a wrong, whether an individual can be blamed for a permissible act, the extent to which the force of rights is dissipated when they are permissibly transgressed. In this article I examine those questions insofar as they are germane to the further question of who should bear those burdens that emerge as the result of permissible harm doing.

Few philosophers would deny that the imperiled hiker, ship captain or diabetic is permitted to act in the way they did. In effect we accept that a right is not a constraint on action when the reasons for permitting self-rescue sufficiently outweigh the reasons for protecting the right. What philosophers do disagree over is whether the burdens that are the product of permissible behavior should be borne by the harmdoer (liability), the rightholder (losses left to lie where they fall) or everyone (members of a private or social insurance pool). For many scholars the answer to that question hinges on the extent to which permissibility extinguishes the moral force of rights.

What I take to be the received view contends that while the imperiled agent did not violate a right, it remains the case that she infringed a right. ${ }^{1}$ The presence of competing demands means she is permitted not to discharge her duty not to transgress. For the same reasons the rightholder is not permitted to

${ }^{1}$ See, in particular, Joel Feinberg, 'Voluntary Euthanasia and the Inalienable Right to Life', Philosophy \& Public Affairs, 7(2) (1978): 93-123 at pp. 101-102; Judith Jarvis Thomson, "Self Defense and Rights", "Rights and Compensation", "Some Ruminations on Rights", and "Remarks on Causation and Liability", collected in her Rights, Restitution and Risk (Cambridge Mass.: Harvard University Press, 1986) and Judith Jarvis Thomson, The Realm of Rights (Cambridge Mass.: Harvard University Press, 1991), pp. 98-103. See also Nancy Davis, 'Rights, Permission, and Compensation', Philosophy \& Public Affairs 14(4) (1985): 374-384; Peter Westen, 'Comment on Montague's 'Rights and Duties of Compensation", Philosophy \& Public Affairs 14(4) 1985: 385-389, David McCarthy, 'Rights, Explanations, and Risks', Ethics 107(2) (1997): 205-225 at pp. 208-210 and Andrew Botterell, 'In Defence of Infringement', Law and Philosophy 27(3) 2008: 269-292. 
prevent the agent from rescuing herself. Even so it remains the case that the stricken agent failed to fulfill a duty and, therefore, that she infringed the correlative claim of the rightholder that she not transgress. In other words, the fact that she acted permissibly does not amount to saying that she did not act in a way that she ought not. Thus, the moral force of the right is not entirely obliterated by the permissibility of her actions. The received view further contends that the residual force that is retained by the infringed right is sufficient to establish the imperiled agent's duty to compensate the rightholder for the destructive costs her actions produced. ${ }^{2}$ This stands in contrast with a rights violation (i.e. impermissible transgression), say the hiker vandalized the cabin, because in that case her duty to compensate cannot be discharged by another and she is, in addition, eligible for some form of punitive treatment.

Against the received view it has been argued that rights disappear without a moral trace in those cases when the actions of the agent are permissible. ${ }^{3}$ That conclusion may be arrived at either by specifying that the right simply ceases to exist in such cases or that the there is a prima facie right that is entirely overridden in such cases. According to the erasure view permissibility entails that the victim does not possess a claimright against the agent, and so the agent has no duty not to

${ }^{2}$ The classic legal case on this issue is Vincent $v$. Lake Erie Transportation Co., 124 N.W. 221 (Minn. Sup. Ct., 1910). In keeping with received view the court found that the defendant acted properly when he did not untie his ship from the plaintiff's dock in order to prevent it from sinking during a violent storm, but ordered him to pay compensation to the plaintiff for the damage that was subsequently caused to the dock. The court also referred to a decision reached two years earlier by the Supreme Court of Vermont in Ploof vs. Putnam, 71 A. 188 (Vt. Sup. Ct., 1908). In that case the court found that the defendant was vicariously liable for losses caused as a result of his employee unmooring the plaintiff's boat from the defendant's dock during a violent storm.

${ }^{3}$ See, for example, Philip Montague, 'Rights and Duties of Compensation', Philosophy \& Public Affairs, 13(1) (1984): 79-88, Russ Shafer-Landau, 'Specifying Absolute Rights', Arizona Law Review, 37 (1995): 209-225 and John Oberdiek, 'Lost in Moral Space: On the Infringing/Violating Distinction and its Place in the Theory of Rights', Law and Philosophy 23(4) (2004): 325-346. 
transgress. Thus, rights only trigger a duty to compensate in those cases where the agent acted impermissibly (i.e. committed a rights violation). It follows from this that a permissible harm doer can only be required to compensate the victim for reasons other than the fact that she transgressed a right.

The position I defend accepts the received view's claim that infringed rights leave a moral trace, but rejects its further claim that the agent has a duty to compensate the rightholder. I argue that liability is unnecessary because the fulfillment of a duty to apologize or express regret is sufficient to accommodate the residual moral force of infringed rights. In support of that claim I argue that the infringer is not liable because she was not presented with an adequate opportunity to avoid the harmful outcome (argument from avoidability) and because the circumstances of peril arose as a result of the agency of innumerable individuals (argument from joint causation). The latter argument also lends support to the claim that the rightholder's losses should be held in common.

I contend that these arguments succeed even if we accept the core components of the received view's argument for the liability of permissible harm-doers - namely that, (i) causation is a necessary condition for the duty to compensate, (ii) rights that have been permissibly transgressed retain moral force, and (iii) an evaluation of the transgressor's reasons for action has no bearing on whether she acted permissibly or has a duty to compensate. This approach differs from the existing responses to the received view in the literature because it does not aim to question one or more of that view's basic premises. I contend that while those three premises provide us with sufficient reason to impose a remedial obligation on the permissible harm doer, they do not provide sufficient reason for insisting that the remedy must be compensatory. The duty to apologize or express regret provides an adequate means for vindicating the victim's rights and for recognizing the causal role of the agent. If that line of argument stands up to scrutiny then the answer to the question of what the permissible harm doer owes the victim does not provide us with an answer to the question of who should bear the burden. 
The article is divided into two principal parts. In Sections I-III, I unpack the basic premises that underpin the received view and demonstrate how those premises are consistent with the nonliability of the permissible harm doer. Sections IV-VII, I present the case against assigning losses due to permissible actions to the agent or victim and for holding such losses in common.

\section{CAUSATION}

According to the received view the fact that A's permissible actions caused $\mathrm{V}$ to suffer a loss provides us with at least prima facie reason for A's duty to compensate V. Equally, A's causal role provides at least prima facie reason not to shift the loss to those individuals who did not causally contribute to the creation of the loss, such as $\mathrm{V}$ or members of an insurance pool. Moreover, that remains the case irrespective of luck in the way things turn out: Thus if, in order to escape a violent storm, A and B tie their identical boats in a likewise fashion to V's dock without his permission and yet only A's boat damages the dock, then only A can have a duty to compensate V.

Evidence for the significance of causation is provided by what Bernard Williams termed 'agent-regret' - the feeling on the part of the agent who caused the harmful outcome that it would have been better if she had done otherwise. ${ }^{4}$ According to Williams the agent's sense of regret remains even in those cases where she was not at fault for causing the harm. Thus, she may still feel regret even though she took extraordinary precautions or her actions were permissible given the circumstances. In addition, agent-regret represents a qualitatively different form of regret than that which may be experienced by a spectator who was not causally involved - boat owner B in the above example may feel regret simply because $\mathrm{V}$ incurred a loss, while boat owner A may feel regret because her albeit permissible actions caused V's loss. Williams goes as far as to argue that the phenomenon of agent-regret reflects the fact that

\footnotetext{
${ }^{4}$ Bernard Williams, 'Moral Luck', in Moral Luck: Philosophical Papers 1973-1980 (Cambridge: Cambridge University Press, 1981), pp. 20-39 at pp. 27-31 and Shame and Necessity (Berkeley: University of California Press, 1993), pp. 132-137.
} 
the consequences of a person's faulty or faultless actions are constitutive their identity as an agent. ${ }^{5}$ Williams further notes that agent-regret involves the expression of regret in various ways, rather than merely being in a state of mind where one feels regret. Thus, a particular agent may think that it is necessary to express her sentiment of regret by compensating the victim or by apologizing. However, the fact that agent-regret arises because of a first-person assessment means that it falls short of establishing that the harm doer should be saddled with a remedial obligation of any description, let alone a duty to compensate the victim. For a particular harm doer may conclude that no expressive response is required or that an apology or voicing of regret suffices. Nor is it necessary that the agent express their regret in order to preserve their identity as an agent. Thus, further argumentation on behalf of the received view is required in order to establish the claim that the agent is required to absorb the loss that she has caused.

Two main lines of argument have been proposed in support of the claim that those who cause a loss have a duty to compensate the victim. According to the first line of argument the agent owns herself, her powers, and, therefore, the losses (or benefits) that flow from the exercise of those powers. Hence, the agent should 'take back' the costs that her actions impose on others by compensating the victim. ${ }^{6}$ According to the second line of argument the agent is liable because she pursued her own ends at the expense of the victim's opportunity to pursue his ends. The victim's freedom of action is constrained either because he is denied what enables him to pursue his ends or because he must devote resources that he would spend pursuing alternative ends to

${ }^{5}$ Williams, 'Moral Luck', p. 29. Tony Honoré's account of outcomeresponsibility also appeals to the idea that good and bad consequences of a person's actions are constitutive of their sense of themselves as an agent. See his Responsibility and Fault, (Oxford: Hart Publishing, 1999), pp. 27-32, 7678.

${ }^{6}$ For a thoroughgoing analysis of the libertarian account of liability see Stephen R. Perry, 'Libertarianism, Entitlement and Responsibility', Philosophy \& Public Affairs 26(4) (1997): 351-396 at 369-373, 375-376. 
repairing or replacing what has been damaged or consumed. ${ }^{7}$ Thus, the agent is liable because she unfairly caused the outcome, and not simply because she causally contributed to its emergence. For the sake of clarity I simply assume that the received view's justification of the causality condition combines both of these strands of argument. Thus, the agent owns the loss in those cases where she pursues her ends at the expense of the victim's opportunity to pursue his ends.

I take it that in order to avoid indeterminacy the causality condition also requires a foreseeability standard. Because the harmful outcome was the product of innumerable causal antecedents (including actions taken by the rightholder, e.g., the cabin owner's loss would not have occurred if he had built the cabin somewhere else or not at all), causality by itself is unable to isolate a particular agent as the unique cause. Thus, a standard of foreseeability is required in order to pinpoint which agent unfairly externalized the costs of their activities. ${ }^{8}$ In cases such as necessity it might appear that foreseeability does not affect the received view's position because the agent who is subject to an emergency can reasonably foresee the outcome that her actions might cause. However, as I argue in Section V, if we apply the foreseeability standard to the emergence of the circumstances of peril, rather than the emergence of the loss

7 See David McCarthy, 'Harming and Allowing Harm', Ethics 110(4) (2000): 749-779 at pp. 756-757, 762, 774 and Judith Jarvis Thomson, 'Critical Study on Jonathan Bennett's The Act Itself', Noûs 30(4) (1996): 545-557 at p. 555 and Thomson (1986, pp. 199-202).

${ }^{8}$ On the need for foreseeability in order to overcome indeterminacy see Stephen R. Perry, 'Responsibility for Outcomes, Risk, and the Law of Torts', in G. Postema (ed.) Philosophy and the Law of Torts (Cambridge: Cambridge University Press, 2001), pp. 72-130 at pp. 91-93. Note, however, the proponents of received view typically assume that foreseeability affects the agent's eligibility for civil liability, but not whether she acted in a way that she ought not. Indeed that stance accords with the idea that unforeseeability does not eliminate agent-regret. See Thomson, 1991, pp. 232-233, 240. Thus, the reason why unforeseeability renders an agent ineligible for civil liability is not that it diminishes the extent of her wrongdoing. A further upshot of this is that a foreseeability standard does not specify the parameters of the victim's right. The agent transgresses the victim's claim-right that she not $\varphi$ even if she cannot reasonably foresee that her actions will cause $\varphi$. 
itself, then it does not follow that the imperiled agent is liable. There is also the sticky question of whether the imperiled agent can avoid the outcome even though she can foresee it. I take up the question of avoidability in Section III.

\section{MORAL RESIDUALISM}

According to advocates of the erasure view the causality condition cannot establish liability because permissibility entails that the victim did not possess a claim-right that the agent not cause the loss. With that challenge in mind I now turn to examine the received view's contention that permissibility does not extinguish the moral force of rights.

The received view rests on the claim that at least part of the moral force of rights does not derive from more basic considerations. ${ }^{9}$ According to the erasure view, by contrast, the moral status of rights is entirely derivative. That is to say, rights do not provide an independent basis for moral assessment. While the received view assumes that a right is one of the moral considerations that enter into our deliberations over whether an action is permissible (i.e. permissibility is in part dependent on the intrinsic value of rights), ${ }^{10}$ the erasure view contends that the existence of a right is dependent on the outcome of those deliberations. ${ }^{11}$ Thus, the latter contends that an individual only has a right if the conclusion of our examination of the moral arguments for and against action is that the agent is not permitted to act. In other words, a right does not exist when the underlying moral reasons for the right (e.g. protection of the victim's basic

\footnotetext{
${ }^{9}$ For one account of the intrinsic value of rights see F. M. Kamm, Intricate Ethics: Rights, Responsibilities and Permissible Harm (Oxford: Oxford University Press, 2007), pp. 28-29, 253-256, 269-271.

${ }^{10}$ See Thomson, 1986, pp. 37, 39.

11 The claim that rights are the conclusions, rather than the premises, of moral argument is perhaps most clearly exampled by the specificationist account of rights. See, for example, John Oberdiek, 'Specifying Rights Out of Necessity', Oxford Journal of Legal Studies 28(1) 2008: 127-146. The prima facie account does presuppose a right, but only as a provisional summary of underlying reasons for the right. Thus, whether in the final analysis an individual has an actual right is dependent on an examination of all the relevant underlying moral considerations.
} 
interest in being able to choose and pursue his or her ends) are outweighed by countervailing considerations (e.g. the imperiled agent's basic interest in avoiding a premature demise). What this also means is that if there is a moral residue in permissibility cases it is not because of the intrinsic value of rights. John Oberdiek, for example, argues that a moral residue emerges because of the inevitable loss of value that arises when incompatible moral reasons are in competition. ${ }^{12}$ The presence of a moral residue, thus understood, does not presuppose the persistence of a right.

For the purposes of this article I simply assume that there are non-derivative reasons for the persistence of rights during times of emergency. However, it is worth noting that accepting the derivative account of rights does not commit us to the view that rights are erased by permissibility. To see this notice how the notion of a rights infringement reflects the fact that permissibility does not amount to saying that the agent's actions were justified or rightful - the reasons against acting remain in place even though they are outweighed (Equally, the notion of a rights violation reflects that fact that the reasons against acting were not outweighed). Thus, recognizing that an infringement occurred is in keeping with the moral residue generated by the conflict between underlying practical reasons. If that is correct then the claim that the victim's rights persist during times of emergency is not at odds with background morality. To the contrary, it serves to capture the normative complexity entailed by moral permissibility. In other words, I take it that we are not necessarily committed to the erasure view even if we reject the claim that rights provide a non-derivative basis for moral assessment.

But how exactly might the received view accommodate the idea that the imperiled agent is allowed to act even though they act as they ought not by doing so? In Hohfeldian terms the received view rests on the contention that the imperiled agent's liberty-right does not entail the absence of the victim's claimright. $\mathrm{V}$ has a claim-right against $\mathrm{A}$ that she not $\varphi$, which is correlated with A's duty not to $\varphi$. At the same time A possesses

\footnotetext{
12 See Oberdiek, 2004, pp. 332-333, John Oberdiek, 'What's Wrong with Infringements (Insofar as Infringements are Not Wrong): A Reply', Law and Philosophy 27(3) 2008: 293-307 at pp. 305-308 and Russ Shafer-Landau, 1995, p. 215.
} 
a liberty against $\mathrm{V}$ to $\varphi$, which means that $\mathrm{A}$ has no duty to $\mathrm{V}$ not to $\varphi$. Moreover, $\mathrm{A}$ has a liberty-right against $\mathrm{V}$ in virtue of the fact that A's liberty is protected by her claim that $\mathrm{V}$ not prevent her from $\varphi$-ing. ${ }^{13}$ According to some advocates of the received view a rights-conflict does not pertain between V's claim-right and A's liberty-right. They contend that $\mathrm{V}$ has a civil claim-right that $\mathrm{A}$ not $\varphi$, but not a criminal claim-right that A not $\varphi$. Equally, A has a criminal liberty-right to $\varphi$, but not a civil liberty-right to $\varphi .{ }^{14}$ Thus, by acting permissibly A commits a civil infringement, but not a criminal violation of V's right. This, I take it, provides one way of capturing the moral complexity entailed by permissibility. ${ }^{15}$

${ }^{13}$ Proponents of the erasure view may argue that because of the fact that $\mathrm{V}$ has a duty not to prevent A from $\varphi$-ing, he does not retain a right of exclusion. Hence, or so the argument goes, B's liberty-right to $\varphi$ entails that V does not retain a claim-right that A not $\varphi$. The received view's response to this challenge is to argue that V's duty is not a consequence of the fact that $\mathrm{A}$ is permitted to $\varphi$. Rather, it is because he (or a bystander) may not act in way that is in itself impermissible (e.g. blocking a person from using the means she has available to escape a deadly predicament) in order to prevent a transgression taking place (i.e. it is because of the fact that preventing $\varphi$ is wrong per se that A's liberty to $\varphi$ acquires the status of a right). According to the received view, therefore, $\mathrm{V}$ is not permitted to apply the right she has to exclude $\mathrm{A}$ from $\varphi$-ing. See Thomson, 1986, pp. 69-70 and Jules L. Coleman, Risks and Wrongs, (Cambridge: Cambridge University Press, 1992), pp. 301, 371-372.

${ }^{14}$ See Westen, 1985, Thomson, 1991, p. 103 and Botterell, 2008, pp. 276278.

${ }^{15}$ In an interesting departure from both the received and erasure views Arthur Ripstein adopts a Kantian position whereby there remains an absolute constraint against transgression in cases of peril. Thus, the actions of the imperiled agent are impermissible (i.e. the imperiled agent has no criminal or civil liberty-right to transgress). However, punitive treatment would be pointless because it would not (prospectively) affect her conduct. That is to say, the threat of (proportionate) punishment is pointless because it will not serve to protect the victim's rights. By contrast the law can compel her to make good the loss generated by the rights violation (i.e. damages for trespass). See his 'In Extremis', Ohio State Journal of Criminal Law 2(2) (2005): 415-434 at pp. 423, 425. Thus, Ripstein arrives at the same conclusion as the received view but based on the claim that acts of necessity entail an (unpunishable) rights violation. Nevertheless, I take it that the arguments I present in the following sections count equally against Ripstein's position and the received view. 
Thus far I have presented what I take to be the strongest case for the liability of the imperiled agent. Namely, an agent has a duty to compensate for losses that she has permissibly inflicted because she has both (i) infringed a right that the victim has and (ii) externalized the costs of her actions. As we have seen advocates of the erasure view reject (i) and, therefore, the claim that the duty to compensate (if there is one) follows from the fact that the agent has transgressed a right. By contrast I contend that a duty to compensate is not required in order to accommodate (i). Rather the duty to apologize or express regret is sufficient to accommodate the residual force of rights that have been permissibly transgressed (i.e. sufficient acknowledgement of the fact that the agent has not fulfilled a duty that she owed the rightholder). If that is correct then the requisite remedial obligation does not provide us with an answer to the question of who should bear the burden.

In response it may be argued that the duty to compensate can be arrived at without appealing to the claim that the imperiled agent infringed a right. Rather it may be based on the victim's claim that the imperiled agent not $\varphi$ without compensating him for the resulting loss. It follows that the agent has a liberty-right to $\varphi$ in virtue of the awaited remedy, rather than simply in virtue of the circumstances of peril. Thus, compensation serves to render the agent's actions permissible, rather than to rectify a wrong that was committed by the agent. ${ }^{16}$ According to this approach instances of private necessity should be seen as analogous with the state's power of eminent domain - e.g. firefighters are permitted to nonconsensually cut down a section of privately owned forest to prevent the spread of a deadly forest fire, provided the state subsequently reimburses the property owner.

The claim-right being elucidated here takes the following conditional form $-V$ has a claim that $A$ not $\varphi$ unless $p_{1} \ldots p_{x}$, where the latter comprises the sufficient conditions for V's claim not to hold. According to the conditioning approach those same conditions also comprise the sufficient conditions for A's liberty-right to $\varphi$ (i.e.

\footnotetext{
${ }^{16}$ See, for example, Robert E. Keeton, 'Conditional Fault in the Law of Torts', Havard Law Review 72(3) (1959): 401-444 and Howard Klepper, 'Torts of Necessity: A Moral Theory of Compensation', Law and Philosophy 9(3) (1990): 223-239.
} 
A has a liberty-right to $\varphi$, if $\left.\mathrm{p}_{1} \ldots \mathrm{p}_{\mathrm{x}}\right)$. Those conditions may include one or more of the following: $\mathrm{V}$ consents to $\mathrm{B} \varphi$-ing, $\mathrm{A}$ is subject to circumstances of peril, $\mathrm{V}$ incurs no loss as result of $\mathrm{A} \varphi$-ing, A compensates $\mathrm{V}$ for the losses $\mathrm{V}$ incurred as a result of $\mathrm{A} \varphi$-ing.

The view under scrutiny accepts that if ex ante consent cannot be acquired (e.g. seeking the rightholder's permission would preclude the possibility of the agent's self-rescue), then it may be substituted for by a combination of the presence of peril and $e x$ post compensation (or presence of peril and absence of a loss). ${ }^{17}$ Thus, if $\mathrm{A}$ inflicts a loss on $\mathrm{V}$ as a result of her attempts to escape a deadly predicament and subsequently refuses to compensate $\mathrm{V}$, then she violates V's claim-right - not because of her failure to compensate per se, but rather because she impermissibly transgressed V's conditional claim-right. However, if both the requisite conditions are fulfilled, then A does not transgress V's right. Equally if $\mathrm{V}$ does not incur a loss as a result of A's self-rescue (i.e. there is no destructive costs and $\mathrm{V}$ is not denied the opportunity to use the property or rent it out), then no transgression took place. This stands in contrast with the received view which insists that A can only avoid transgressing V's claim-right if she obtains V's prior consent. When A acts nonconsensually the presence or absence of peril merely serves to determine whether the transgression constituted an infringement or a violation. Even if $\mathrm{V}$ incurred no loss as a result of A's nonconsensual self-rescue it remains the case that A denied V's right of control over how his right is used. Thus, the received view contends that compensation serves to correct rather than to avert a transgression.

I take it that the conditioning approach may be seen as a variation of the erasure or received view. According to the first

${ }^{17}$ This conditioning approach is in keeping the distinction between property rules and liability rules that is employed by exponents of the economic analysis of law. See Guido Calabresi and A. Douglas Melamed, 'Property Rules, Liability Rules, and Inalienability: One View of the Cathedral', Harvard Law Review 85(6) (1972): 1089-1128. According to the former type of rule the agent is legitimately entitled to $\varphi$ only if the rightholder consents to the transfer. According to the latter, the agent's compensation of the rightholder for the value of $\varphi$ is sufficient to legitimate the agent's entitlement to $\varphi$. In those cases where the agent is subject to peril the protection afforded to property is relegated from property rules to liability rules. 
interpretation V's claim-right that $\mathrm{A}$ not $\varphi$, is erased if $\mathrm{A}$ is subject to peril and compensates $\mathrm{V}$ after the fact. It other words, A can only avoid committing a rights violation if both conditions are satisfied. ${ }^{18}$ According to the second interpretation, the absence of consent means that V's claim-right is not entirely erased by the fulfillment of those two conditions and yet they are both necessary conditions for A's liberty right to $\varphi$. In other words, it is only if both conditions are satisfied that A's transgression constitutes an infringement as opposed to a violation of V's claim-right. The conditioning approach, therefore, does not necessarily entail a rejection of moral residualism.

As I see it the problem with the conditioning approach is that it begs two questions: (i) Why is exposure to peril not a sufficient condition? And, (ii) if imperilment is not sufficient, why is compensation as opposed to some other response by the agent (e.g. formal apology) the further condition that is required? By way of illustration, consider the case of a mistaken payment that is innocently received. Although the recipient infringed no right in receiving the payment, she is required to return it in virtue of the fact that she does not have a right to it. By contrast, the hiker who breaks into a cabin so as to escape a life-threatening blizzard has a right to consume the cabin owner's food and burn his furniture insofar as it is necessary escape the deadly predicament. Her liberty-right in virtue of peril means that she did not cause a loss beyond what she had a right to and so it is not clear why compensation should be included as further condition of that right. If, however, the imperiled hiker accidentally consumes more food than is necessary to survive, then she may be required to pay the owner the value of that excess for the same reasons as the recipient of a mistaken payment is required to return it to its rightful owner. ${ }^{19}$ What this suggests is that even if the imminent threat of peril is not a sufficient condition for the agent's liberty-right we

18 See Shafer-Landau, 1995, p. 216 and William A, Parent and William J. Prior, 'Thomson on the Moral Specification of Rights', Philosophy and Phenomenological Research LVI(4) (1996): 837-845 at pp. 840-843.

${ }^{19}$ A similar line of argument is developed by Dennis Klimchuk in his 'Necessity and Restitution', Legal Theory 7(1) (2001): 59-81 at pp. 69-71. 
may ask why making good the victim's loss, as opposed to say apologizing, must comprise the further condition.

Indeed there is, I contend, good reason to saddle the imperiled agent with a duty to apologize rather than a duty to compensate - whether as a further condition that is built into the victim's claim-right or, as a subsidiary duty following from the fact that the agent infringed the victim's claim-right. Compare the case of the hiker who breaks into a cabin to avoid death by exposure with the case of the hiker who burns down part of a cabin as a result of failing to adequately extinguish a campfire. The problem with the received view and the conditioning approach is that they prescribe a duty to compensate in both cases even though the gravity of the wrong committed by the negligent hiker is clearly greater. My approach allows us to differentiate between these two instances of civil wrongdoing because the imperiled agent is only saddled with a duty to apologize or express regret.

\section{FIRST-ORDER MORALITY}

I now turn to clarify the third basic premise of the received view; namely, the irrelevance of the effect of peril on the agent's will. According to the received view it is important to distinguish between three types of question: Is A allowed to $\varphi$ ? Who should bear the burden that results from A having $\varphi$-ed? Is A eligible for moral criticism for $\varphi$-ing? Only the latter question requires that we take into account the content and attributability of the agent's reasons for action. In other words, what the agent was thinking when she acted (second-order morality) has no bearing on the permissibility of her actions or whether she must bear the burden (first-order morality). ${ }^{20}$ Thus, the received view contends that the effect of the emergency on the agent's reasons for action only becomes relevant when we turn

${ }^{20}$ The distinction between these two orders of morality was originally drawn by Alan Donagan, The Theory of Morality (Chicago: Chicago University Press, 1977), p. 55 and subsequently further developed by Jonathan Bennett, The Act Itself (Oxford: Clarendon Press, 1995), pp. 46-49. Here I extend Donagan and Bennett's account by including the assignment of burdens within the scope of first-order morality. 
to consider whether it would be appropriate to praise or blame the agent for what she has done. What this means is that the agent who responds to an emergency may attract noncriminal liability even though her actions were permissible and blameless, perhaps even praiseworthy - say, because we admire her quick thinking under adversity or because she infringed in order to rescue another from peril.

Let us firstly consider the application of first-order morality to the question of whether the agent was allowed to act as they did. According to proponents of the received view the permissibility of an action does not depend on whether the harmful outcome was intended or ill-intended. ${ }^{21}$ All that is required for permissibility is that the agent acted in a way that was consistent with a predefined standard of conduct (e.g. an agent is permitted to transgress when it is necessary to avoid a greater evil of sufficient magnitude). In other words, we need not examine the transgressor's reasons for action in order to determine whether she has committed an infringement or a violation. Thus, the fact that hiker intends to damage the cabin in order to escape a blizzard does not mean that her actions are less permissible than the boat owner who does not intend to damage the dock when she seeks safe harbor during a violent storm. Equally, the reasons why the permissible harm doer acted have no bearing on whether the victim's right perseveres. Thus, it remains the case that the boat owner failed to fulfill a duty that she owed the dock owner even though she did not intend to cause any damage to the dock. ${ }^{22}$

${ }^{21}$ See, for example, Judith Jarvis Thomson 'Self-Defense', Philosophy \& Public Affairs 20(4) (1991): 283-310, Section V; and 'Physician-Assisted Suicide: Two Arguments', Ethics 109(3) (1999): 497-518. David McCarthy, 'Intending Harm, Foreseeing Harm, and Failures of the Will', Nô̂s 36(4) (2002): 622-642. Nancy Davis, 'The Doctrine of Double Effect: Problems of Interpretation', Pacific Philosophical Quarterly 65 (1984): 107-123.

22 According to the received view permissibility is also unaffected by whether the agent could objectively or subjectively foresee the harmful outcome. The fact that we could not reasonable expect the agent to foresee the outcome is a first-order consideration that speaks to the question of who should bear the burden, but not to the question of whether the agent acted as she ought not. By contrast, the fact that the agent did not actually foresee the outcome is a second-order consideration which has no bearing on either question. 
Permissibility is also unaffected by whether an agent transgresses because of the reasonable but mistaken belief that she is subject to peril (e.g. A falsely assumes that B is threatening her life). In such cases advocates of the received view maintain that the agent's transgression is impermissible and that the rightholder may, therefore, exercise his right to exclude. ${ }^{23}$ As a second-order matter, however, she may be praised (e.g. for rescuing a person she mistakenly believes to be imperiled) and excused of committing the rights violation if her mistake is deemed to have been reasonable. Nevertheless, she remains eligible for noncriminal liability.

Let us now turn to consider the application of first-order morality to the question of who should bear the burden. As we have already observed the received view is committed to the claim that moral permissibility does not entail a complete legal justification - while the stricken agent's actions may have been criminally justified (i.e. did not contravene a criminal duty not to $\varphi$ ), it remains the case that her actions were civilly unjustified (i.e. contravened a civil duty not to $\varphi$ ). This stands in contrast with the erasure view which contends that moral permissibility does entail a complete legal justification (i.e. the imperiled agent committed neither a criminal nor a civil transgression). According to the received view, therefore, the imperiled agent has duty to compensate because her actions entail that she committed a noncriminal wrong against the rightholder and caused a loss to the rightholder.

In response to this it may be argued that the effect of the emergency on the agent's reasons for action means that she is not sufficiently responsible for committing the civil wrongdoing and, therefore, she should not be saddled with a duty to com-

23 Taking the opposing view Kent Greenwalt has argued that the reasonable but mistaken belief that justifying conditions pertain, qualifies as a justification. See his 'The Perplexing Borders of Justification and Excuse', Columbia Law Review 84(8) (1984): 1897-1927 at pp. 1919-1920. However, as Alan Brudner notes, Greenwalt assumes that an assessment of the agent's reasons for acting in response to the (mistaken) emergency is relevant to the question of whether those actions were justified. Alan Brudner, 'A Theory of Necessity', Oxford Journal of Legal Studies 7(3) (1987): 339-368 at pp. 364365. 
pensate the rightholder. George Fletcher, for example, has argued the case for the relevance of excusing conditions to noncriminal liability. ${ }^{24}$ In cases of peril I take it that although the agent is presented with options, she finds herself unable resist one of them. Thus, while the hiker who is exposed to a life threatening blizzard does in fact have the option not to break into the cabin, she is unable to withstand her desire to avoid the consequences of not doing so. ${ }^{25}$ Of course, she could have been moved to act by reasons other than the desire to protect life and limb, but it would overstrain human nature to expect her to be able to do so. ${ }^{26}$ Even an orthodox stoic, who is convinced that for the sake of her inner well-being she should die rather steal or damage another person's property, may not be able to resist the desire to preserve herself. The orthodox stoic could theoretically have been moved to act by reasons other than the desire to preserve herself, but it would be asking too much to expect that even she would be able to resist the urge to do so. This suggests that the imperiled agent did the best that we can expect of a person of reasonable fortitude and, therefore, that she is should not be held responsible for committing the wrong. It follows, or so the argument goes, that she should not bear the burden created by her wrongdoing.

${ }^{24}$ George P. Fletcher, 'Fairness and Utility in Tort Theory', Harvard Law Review 85(3) (1972): 537-573 at pp. 551-553.

${ }^{25}$ In addition it may be argued that the imperiled agent is not responsible for her actions if the fact that she fears for her life means that she cannot think straight. In that case the agent's reasons for action are not attributable because her judgment is impaired, rather than because of the irresistibility of the desire to self-preserve. On impairment as an excuse when the agent is subject to an irresistible desire see Gary Watson, 'Excusing Addiction', in Agency and Answerability: Selected Essays (Oxford: Oxford University Press, 2004), pp. 318-350 at pp. 337-338.

${ }^{26}$ Here I differ from Harry Frankfurt who implies that the imperiled agent does not have an alternative because it is impossible for her to resist the desire to self-preserve. See Harry G. Frankfurt 'Coercion and Moral Responsibility', in The Importance of What We Care About (Cambridge: Cambridge University Press, 1988), pp. 26-46 at pp. 42-46. See also his 'Alternative Possibilities and Moral Responsibility', pp. 1-10 at pp. 2-4 in the same volume. 
As we have already observed the received view responds to this challenge by arguing that the effect of peril on the agent's will speaks to the question of blameworthiness and not to the distinct question of who should bear the cost. Thus, that view holds that the imperiled agent must bear the burden irrespective of her eligibility for moral criticism. The effect of peril on the content (i.e. not moved to act by a malign motive) and attributability (i.e. desire to avoid a premature demise is virtually irresistible) of her reasons for action simply has bearing on whether she should take back the cost she has caused.

My primary aim in this section has been to elucidate the third central plank of the received view's argument for the liability of permissible harm doers. With that in mind I will shortly present two arguments against liability for permissible transgressions that follow even if we accept the irrelevance of second-order morality. Nevertheless, we may ask why we should insist that those factors that count against blaming the imperiled agent for committing the infringement should not also count against her civil liability. I take it that central concern of the received view is that if excusing conditions are deemed to be pertinent, then too much emphasis would be placed on the doer to the detriment of the sufferer. ${ }^{27}$ As a result the doer and sufferer are not treated equally - the sufferer is treated as a means to the doer's ends. The assumption being made here is that taking back the burden created by one's actions is required in order to restore equality between the parties. But that assumption does not countenance the possibility that an apology or expression of regret is sufficient to vindicate the sufferer's rights. Moreover, that requirement may provide a fitting way to express any residual blame that we might attach to the imperiled agent's actions. Because it

${ }^{27}$ Peter Cane, Responsibility in Law and Morality (Oxford: Hart Publishing, 2002), pp. 49-51, 106-107 and Ernest J. Weinrib, The Idea of Private Law (Cambridge: Cambridge University Press, 1995), p. 54. A related concern is that first person moral evaluation would expose the victim to the peculiarities of the agent (e.g. the circumstances of necessity may be created by an agent's unusual phobia). This problem can be overcome by introducing an ordinary person standard for excusing conditions. Notice, however, that this represents an argument against individualizing excusing conditions and not against the relevance of excuse itself. 
remains possible for the agent to act according to reasons other than the desire to protect life and limb it might be argued that she remains partially responsible for her failure to fulfill the duty she owed the rightholder. ${ }^{28}$ Thus, the requirement to apologize or voice regret would simultaneously accommodate our evaluation of the agent's will and the preeminence of the victim's rights. ${ }^{29}$ It is by no means clear, therefore, why it is necessary to disregard excusing conditions when we are considering who should bear the burden resulting from a permissible transgression.

\section{THE ARGUMENT FROM AVOIDABILITY}

Thus far I have posited that all the central tenets of the received view - causation as a necessary condition for bearing the burden, the residual force of infringed rights and the irrelevance of second-order morality - are consistent with non-liability. A duty to apologize or express regret accommodates all three conditions and provides a way of ensuring that the rights of the victim are vindicated. Moreover, we have seen how a nonpecuniary duty allows us differentiate the agent who transgresses because of peril from the agent who transgresses because they failed to exercise reasonable care. What this means is that the answer to the question of what remedy the permissible transgressor owes the rightholder does not provide us with an answer to the question of who should bear the burden. Nevertheless, defenders of the received view may insist that compensation is the required remedy, say because the infringer owns those losses that (foreseeably) result from the exercise of her powers. With that in mind I now shift the focus of attention to explicitly arguing against liability for permissible transgres-

\footnotetext{
${ }^{28}$ On the idea that excusing conditions may not fully exonerate the wrongdoer see J.L. Austin, 'A Plea for Excuses', Proceedings of the Aristotelian Society 57 (1956-7): p. 3.

${ }^{29}$ As we noted in Section I an apology or voicing of regret might also provide a means of expressing agent-regret. That differs from the present proposal because blaming treatment serves to express our assessment of the agent, rather than a first-person assessment by the agent themselves. Nevertheless, both these sources of reactive emotion provide support for the idea that some form of remedial response would be fitting.
} 
sions. In this and the next section I present two arguments against assigning the burden to the infringer that follow even if we accept all three of the received view's basic tenets.

According to first argument, individuals should only bear those burdens for which they had the adequate opportunity to avoid. ${ }^{30}$ The underlying idea here is that in determining who should bear a burden (e.g. injury, obligations, punishment, censure etc.) we should remain sensitive to the value we place on being given a choice. That is to say, we have generic reasons for wanting what happens to us depend on the way we choose given the right conditions. ${ }^{31}$ Thus, an individual has legitimate grounds for complaint if they end up with a burden that they did not have the fair chance to avoid. This stands in contrast with moral appraisal which does not require that the agent has an alternative course of action available to them (e.g. we may still blame the drug addict who wants her will to be determined by a desire that it is not possible for her to resist).

In cases of peril the adequate opportunity to avoid the burden is denied both because of the effect of peril on the agent's capacity to choose otherwise and because of the impoverished choice set that confronts her. In other words, second-order and first-order considerations play a role in determining the extent to which a burden was avoidable. In the first case, the agent's opportunity to avoid the loss is

${ }^{30}$ The argument I present here draws on the distinction that T.M. Scanlon makes between 'attributive' and 'substantive' responsibility in his What We Owe to Each Other (Cambridge Mass.: Harvard University Press, 1998), chapter. 6 and Moral Dimensions: Permissibility, Meaning, Blame (Cambridge Mass.: Harvard University Press, 2008), pp. 198-206. See also H.L.A. Hart, 'Legal Responses and Excuses', in Punishment and Responsibility: Essays in the Philosophy of Law, 2nd edition (Oxford: Oxford University Press, 2000), pp. 28-53 at pp. 44-48; Gary Watson, 'Two Faces of Responsibility', in Agency and Answerability: Selected Essays (Oxford: Oxford University Press, 2004), pp. 260-288 at p. 280. Here, however, I apply the idea of a fair chance to avoid harm to the justification of liability, rather than to the justification of blaming treatment.

${ }^{31}$ On the value we attach to choice see Scanlon (1998, pp. 251-254) and Scanlon, The Significance of Choice in S.M. McMurrin (ed.) The Tanner Lectures on Human Values, Vol. VIII (Salt Lake City: University of Utah, 1988), pp. 177-185. 
compromised by the fact that she is overwhelmed by the desire to preserve herself or because her judgment is impaired by the fact that she is consumed by fear. In the second case, the imperiled agent is presented with two costly alternatives, one of which is prohibitively costly. The fact that she lacks access to an alternative that will not impose a significant cost on herself or another, means that she is deprived of a fair chance to avoid harm. The concern here is not the number of choices available to the agent, but rather the absence of at least one (objectively) decent alternative. This notion of inadequacy rests on the absence of a satisfactory alternative, rather than on the fact that the agent cannot be expected to resist avoiding the prohibitive cost. We do not need to know how and why the imperiled agent actually chose to act in order to conclude that she should not bear the burden. The absence of a decent alternative in her choice set suffices. Thus, we may conclude that the burden is not adequately avoidable even if we disregard the effect of peril on the agent's will.

It might be argued that this cannot be right because it would mean that an imperiled agent who is moved to transgress by malign motives (e.g. revenge), rather than the desire to selfpreserve, both would have acted permissibly and would escape liability. However, this example does not pose a challenge to the view that I am defending. In the first place it may be argued that while the agent who acts based on revenge is eligible for moral criticism, it remains the case that she is not responsible for the outcome in virtue of the fact that she lacked access to an adequate alternative. In the second place, we may concede that the vengeful agent is liable in virtue of her reasons for action. But if that is the case then we must also concede that the evaluation of the agent's reasons for action is relevant to the question of who should bear the burden. Thus, we end up back with the proposal, examined in the previous section, that the imperiled agent is non-liable in all but those rare cases when the agent is unmoved by the desire to self-preserve.

A further upshot of this argument is that in cases of peril neither the agent nor the victim was presented with an adequate opportunity to avoid the harmful outcome and so neither 
should be left to bear the burden. In other words, it does not entail that the loss must simply befall the victim. Nevertheless, it remains the case that the agent used the victim's rights without his consent, and so an apology or expression of regret is called for. Equally, from the perspective of the agent, that requirement is justified because it remains the case that she 'had the choice'. However, the imposition of a further duty, such as a duty to compensate, would be unjustified because she was not presented with an adequate choice. This cannot be the whole story though because while it explains what is required in order to adequately vindicate the victim's rights, it does not provide us with a determinate answer to the question of who should bear the burden. In Section VI I argue that the causality condition that is presupposed by the received view provides us with an explicit justification for spreading losses due to acts of necessity between everyone. That is to say, I argue that the entire burden should not be borne by the victim or the agent, nor shared between them. Rather they should share the burden along with all other members of the political community.

In response to the argument from avoidability advocates of the received view may argue that the mere presence of an alternative course of action is sufficient to accommodate the value of choice. That is to say, liability does not hinge on the adequacy of the choosing conditions that confront the agent. Thus, the imperiled agent remains liable because she can as a matter of fact choose otherwise. However, it is difficult to see how the value of choice is satisfactorily accommodated if the agent virtually cannot abstain from being moved by the desire to self-preserve and where the only other alternative in her choice set is almost certain death or serious injury. Nevertheless, I will shortly argue that once we take into account the origin of the circumstance of necessity we have an argument for non-liability that follows even if we accept that the quality of the conditions for choice is irrelevant.

Finally, it might be argued that we should focus not on the quality of choice that confronts the imperiled agent, but rather her antecedent choices that causally contributed to the emergence of the deadly predicament (e.g. her prior decision to go 
hiking). In the following section I turn to examine the issue of the origin of necessity in detail. However, the argument from avoidability already suggests that the emergency should only be the imperiled agent's problem if they were presented with a fair opportunity to avoid exposure to it. It follows that, insofar as the emergency was not reasonably foreseeable (e.g. freak storm), the imperiled agent should not incur the burden resulting from her response to it.

\section{THE ARGUMENT FROM JOINT CAUSATION}

In the preceding sections I have focused on the question of whether the agent's choice in response to the circumstance of peril means that she is responsible for the harmful outcome. But there is a prior issue that should be examined more carefully: namely, whether the circumstances of peril is the agent's problem in the first place. If the predicament is not the agent's problem then we may doubt that she should bear the burden created by her life saving actions. I shall argue that the received view's commitment to the causality condition means that it cannot avoid the conclusion that the emergency is everyone's problem.

The received view presupposes that the deadly predicament befalls the endangered agent in all but those cases where it was brought about by another individual (e.g. where the agent is acting in self-defense in response to an act of aggression or responding to a coercive threat). In those cases where the predicament is the result of another person's actions then liability can be tracked back to them. ${ }^{32}$ Thus, it remains the case that the predicament befalls the agent in those cases where they are subject to an unforeseeable natural event such as a freak storm or lightening strike. The predicament is simply their bad luck rather than their responsibility, as would be the case if it were foreseeable and avoidable. While the agent could not have reasonably foreseen the predicament, it remains the case that her prior choices led her to become exposed to the predicament - for example, if the hiker had not decided to go hiking on that

${ }^{32}$ See Arthur Ripstein, Equality, Responsibility and the Law (Cambridge: Cambridge University Press, 1999), pp. 114-115. 
particular day and in that particular area she would not have been exposed to the freak storm. Thus, according to the received view the fact that the imperiled agent is confronted by a choice between a prohibitive cost and a less prohibitive cost is her problem. The course of action she chooses to take in response to the emergency merely serves to determine the type of cost she will bear.

I contend that the received view's claim that the problem befalls the imperiled agent is ultimately dependent on an unargued assumption. Namely, that the causality condition applies to the destructive costs resulting from the agent's response to the circumstances of choice, but not to the emergence of the circumstances of choice itself. Consider the case of the hiker caught in a life threatening blizzard. But for the fact that the meteorologist had forecasted fine weather, the local authorities had decided to mark out a trail in that area, the fact that a friend had recommended the trail to the hiker, the fact that a traffic accident blocked the road in the direction of the area that the hiker had originally planned to hike and so on, the circumstances of peril would not have occurred. The set of causes is multiplied if we accept that acts of omission (e.g. the local authority's decision not to build an emergency shelter in the hiking area) qualify as a cause. ${ }^{33}$ The predicament is the result of innumerable antecedent decisions by agents other than just the one who must respond to it. Note that the point that is being made here is not the familiar one that causal indeterminacy means that we cannot isolate the unique cause of the harmful outcome. ${ }^{34}$ Rather it is that causal indeterminacy means we cannot pinpoint the imperiled agent as the unique

${ }^{33}$ See, for example, Judith Jarvis Thomson, 'Causation and Rights: Some Preliminaries', Chicago-Kent Law Review 63 (1987): 471-521 at pp. 494-495 and Judith Jarvis Thomson, 'Causation: Omissions', Philosophy and Phenomenological Research 66(1) (2003): 81-103.

${ }^{34}$ In the tort law literature the fact that every injury is jointly produced has been used to show that causation is not sufficient for liability, See Ronald Coase, 'The Problem of Social Cost', Journal of Law and Economics 3(1) (1960): 1-44 and Guido Calabrasi, 'Some Thoughts on Risk Distribution in Torts', Yale Law Journal 70 (1961): 499-553. The novelty of the line of argument presented here is that it is focuses on the absence of a unique cause of the deadly predicament, rather than the harmful outcome. 
cause of the circumstances of choice. In other words, the upshot of the received view's reliance on the causality condition is that the deadly predicament is not simply a problem created by those who are confronted by it. If that is correct we may ask why the stricken agent should bear the burden created by her response to that predicament.

One strategy that may be adopted by proponents of the received view in response to this challenge is to show that causal role of the imperiled agent in producing the circumstances of peril is relevant, while the causal role of other agents in producing those circumstances is not. As I noted in Section I the received view can overcome the problem of indeterminacy with regard to the harmful outcome by appealing to an objective standard of foreseeability. I take it that the equivalent standard is required in order to mitigate the problem of indeterminacy with regard to the predicament. For without it the received view has no way of picking out the unilateral cause of the emergency from amongst the countless antecedent doings and non-doings. In addition, the foreseeability standard is consistent with the principle introduced in the previous section that individuals should only be left to bear those burdens that they had the fair chance to avoid.

However, even if we apply that criterion of avoidability to the question of whose problem the emergency is, it would remain the case that agents who are afflicted by a freak natural event, such as the hiker or ship captain, are not responsible for their predicament. Equally we cannot delegate responsibility to anybody else unless it was reasonably foreseeable that their actions would bring about the predicament (e.g. coercive threat or act of aggression). Thus, from amongst those that unforeseeably contributed to the emergence of the deadly predicament, none can be isolated as the unique cause.

The advocate of the received view might go on to argue that the predicament befalls the imperiled agent because she intentionally took take part in an activity (e.g. driving, hiking, walking down the street etc.) where there was a risk of exposure to an emergency. From amongst the countless individuals who causally contributed to the emergence of the predicament, it 
was only the imperiled agent who was pursuing her aims by partaking in the particular activity. The underlying idea here is that particular risks are assigned to particular activities. Hence, the risk that the hiker may become exposed to an unforeseeable and deadly blizzard is assigned to the hiker and not to those other activities, performed by others, that may have causally contributed to the emergence of the predicament (e.g. weather forecasting, trail building, road building etc.). That is to say, it is not within the risk of those other activities. I take it that the primary justification for the application of the risk rule is the need to strike an appropriate balance between our interests in avoiding injury and our interests in being free to pursue our ends. Thus, an overemphasis on our security interests would only serve to unreasonably circumscribe our liberty interests, and vice versa. ${ }^{35}$ However, the idea of tracing responsibility for the predicament back to the myriad actions that unforeseeably contributed to its emergence does not entail that any particular individual is saddled with an obligation not to act in the way they did. Thus, it does not entail the limitation of any particular individual's freedom of action. Rather there is only a duty where it is possible for any individual to take reasonable precautions against foreseeably causing the emergence of circumstances of necessity. It is not clear, therefore, that the risk of exposure to an unforeseeable predicament should be assigned to the participant in any particular activity.

It take it that, therefore, the only remaining response available to the defender of the received view is to argue that that it is purely bad luck and not agent causation that determines whose problem the predicament is. That is, if all those who were causally implicated exercised sufficient care then the misfortune simply lies where it falls. But if so they would need to explain why the causality condition is relevant to the question of who should bear the burden and yet irrelevant to question of whose problem the predicament is. Even though the received view is ultimately reliant on the claim that agent causation applies to burdens but not predicaments, it does not provide us with principled account of why we should make such a

\footnotetext{
${ }^{35}$ See, for example, Ripstein, 1999, pp. 50-52, 71-72.
} 
distinction. As a result, it does not establish that the (unforeseeable) emergency is the imperiled agent's problem and, therefore, that she should bear the cost of her response to that predicament.

\section{HOLDING LOSSES IN COMMON}

It may be argued that if the predicament does not befall the imperiled agent then we end up disregarding the security interests of the victim of the agent's life-saving actions. If by security interests we mean the victim's interest in not having what happens to him depend on the choices of others then we already have a remedial measure in place. For the agent owes the victim a formal apology for denying the victim's right of control over how his right is used. Thus, it is only with respect to the denial of the means that the victim would have had to pursue his personal ends that we run the risk of disregarding his security interests. Indeed, the implication of the arguments from avoidability and joint causation is that the entire loss should not befall the victim, let alone the agent. Thus, we still have not arrived at an determinate answer to the question of who should bear the burden. However, the lack of a defensible alternative already suggests that losses due to permissible transgressions should be borne by everyone.

However, we need not arrive at the conclusion merely by default. For the argument from joint causation does provide us with a rationale for the holding such losses in common. The upshot of that argument was not so much that the (unforeseeable) predicament does not belong to the imperiled agent, but rather that it belongs to everyone. If that is the case, then it is hard to see why the imperiled agent alone should be made responsible for the cost of her response to that predicament. Rather, the joint (and unforeseeable) causation of the circumstances of peril suggests that losses that arise because of a permissible response to those circumstances should be spread amongst members of a mandatory social insurance pool.

Defenders of the received view typically argue against loss spreading on the grounds that an individual's membership of the insurance pool is not determined by their causal role in 
producing a misfortune. ${ }^{36}$ Some rationales for loss spreading do abandon the causal link between the action and the effect. For example, mandatory insurance may be advocated on the grounds that it helps to factor out luck in the way things turn out - the underlying concern here is that of two agents who behave in a similar way in similar circumstances, the intervention of luck between the action and outcome may mean that only one may cause a loss, or there may be a significant difference in the extent of the loss each causes. ${ }^{37}$ Alternatively, insurance may be imposed so as to encourage cooperation that is mutually advantageous - potential risk creators are encouraged to participate because they will avoid the possibility of being burdened with a massive loss and potential victims of risk are encouraged to participate because compensation is certain. In both these cases an individual's membership of the insurance pool is determined by the fact that they are engaging in an activity that creates the risk of a misfortune (e.g. risk of being exposed to a deadly blizzard). Hence, their contribution to the compensation of a loss is not determined by whether they in fact played a role in causing that loss (e.g. breaking into an unoccupied log cabin).

Those arguments may be used in support of loss spreading in cases of peril. However, they do not, in themselves, rule out dispersing losses in those cases where the predicament was foreseeably created (e.g. going hiking when inclement weather was forecasted) and in those cases where the imperiled agent's reaction is impermissible (e.g. hiker damages more of the cabin than is necessary in order to escape peril). By contrast the argument I am presenting only advocates holding in common those losses that were caused by a permissible response to an unforeseeable emergency. Moreover, that argument does not discount the causal connection between the agent and the outcome. Rather it contends that responsibility cannot be

\footnotetext{
${ }^{36}$ See for example, Weinrib, 1995, pp. 36-38.

${ }^{37}$ See, for example, Jeremy Waldron, 'Moments of Carelessness and Massive Loss', in David G. Owens (ed.) Philosophical Foundations of Tort Law (Oxford: Clarendon Press, 1995), pp. 387-408 and Christopher $\mathrm{H}$ Schroeder, 'Corrective Justice, Liability for Risks, and Tort Law', UCLA Law Review 38 (1990): 143-162.
} 
pinned to any particular agent because the deadly predicament was jointly caused by innumerable agents. In other words, in keeping with the causality condition, membership of the insurance pool is determined by (unforeseeable) causation, rather than risk imposition.

Note, however, that holding such losses in common does not amount to saying that privately owned resources revert to being owned in common during times of emergency (e.g. a privately owned cabin becomes a public financed emergency shelter insofar as it required by someone in distress). That much is clear from the fact that if imperilment converts a life saving resource into a public commodity, then no compensation would be owed to the private rightholder. Moreover, I have argued that the imperiled agent has a duty to apologize in virtue of the fact that she infringed the victim's right.

It may be argued that, if joint causation of the predicament rules out holding the imperiled agent liable, then it should also rule out a saddling her with a remedial obligation of any kind. However, I take it that that challenge does not amount to saying that the victim's right does not persist in virtue of joint causation. That is, in keeping with the received view, it accepts that the stricken agent failed to fulfill a duty that she owed the rightholder. But it does not seem tenable to hold both that an agent breached a duty that she owed the victim and that she owes no remedial duty to the victim in virtue of that breach. In some cases the transgressor may be permitted not to perform their remedial duty (e.g. it may conflict with an overriding duty), but that does entail that the agent ceases to have such a duty. Even if it is argued that the logic of rights does not commit us to the conclusion that a remedial duty is necessarily entailed by the transgression of a claim-right, it remains the case that there ought to be some means of vindicating the victim's rights. That is, a way of recognizing that the victim does have a right and that that right was transgressed by the agent.

I have argued that losses due to permissible transgressions should be held in common both because of the absence of a satisfactory alternative and because the emergency is a joint 
product. For reasons of space I shall not flesh out that line of argument in more detail. Note, however, the plausibility of the argument for loss spreading does not affect the plausibility of the negative conclusion, developed in the preceding sections, that liability does not follow from the core premises that undergird the received view.

\section{PERMISSIBLE INTERVENTIONS}

The focus of the discussion thus far has been permissible acts of self-rescue. Before concluding it is worth considering whether we can extend the joint causation argument to those cases in which an individual permissibly transgresses on behalf of another (e.g. rescuing an imperiled hiker by breaking into a cabin or destroying an individual's house so as to prevent the spread of a deadly forest fire).

According to the received view bystander B is liable if she permissibly transgresses V's rights in order to effect the rescue of A. I take it that that the received views argument for that conclusion rests on the assumption that there is a stronger normative constraint against causing harm, than there is against allowing harm. In other words, while B ought to effect A's rescue, she is not duty bound to do so. ${ }^{38}$ As a matter of second-order morality $\mathrm{B}$ is eligible for moral criticism if she fails to carry out a rescue. However, as a matter of first-order morality her failure to do so is not impermissible (i.e. not a breach of a duty she owes imperiled agent). That is, the reasons why B ought to rescue A, and therefore why a transgression of V's right would be permissible, are not sufficient to establish that she has a duty to rescue $\mathrm{A}$. What this means is that the deadly predicament that befalls $\mathrm{A}$ does not trigger a strict requirement that $\mathrm{B}$ perform the rescue (although it should be noted that B would have a Good Samaritan duty in those cases

${ }^{38}$ On the absence of a duty to rescue see, for example, Thomson, 1986, pp. 61ff and 1990, pp. 160-163. According to the received view the rightholder has a duty not to prevent a permissible self-rescue and the state may use coercion to enforce that duty. However, the impermissibility of preventing self-rescue does not entail that the rightholder himself has a duty to rescue. See Thomson, 1991, pp. 113-115, 117 and McCarthy, 2000, p. 772. 
where she foreseeably caused the predicament). From that it follows that the cost caused by B's permissible intervention cannot be traced back to A.

One problem with this account of permissible interventions is that it generates a counter-intuitive conclusion in those cases where the individual who is rescued is also the rightholder. By way of illustration consider the following variation on the hiker example: During a blizzard B stumbles across A who has been rendered unconscious as a result of hyperthermia. B rescues $\mathrm{A}$ by breaking into a nearby cabin. Unbeknownst to B the cabin belongs to $\mathrm{A}$. The upshot of the received view is that $\mathrm{B}$ has a duty to compensate A for the damage she caused to the cabin. Even the imposition of a duty to apologize seems entirely unjustified in such cases. One of the advantages to be gained from extending the argument from joint causation to cases of rescue is that it avoids that counter-intuitive outcome.

In keeping with the received view let us assume that $\mathrm{B}$ does not have a duty to rescue A. To that add the further claims, defended here, that unforeseeable emergencies are everyone's problem and that losses due to permissible responses to such emergencies should be held in common. It follows that if $\mathrm{B}$ decides to intervene, then the resulting burden to $\mathrm{V}$ or $\mathrm{B}$ is borne by everyone. The same conclusion follows in those cases where the intervening agent permissibly kills some in order to save many - for example, a bystander switches the tracks such that a runaway trolley is diverted away from the path of five railway workers and into the path of one railway worker. ${ }^{39}$

We have seen how losses should be held in common in those cases where an agent permissibly transgresses in response to perilous circumstances and how that conclusion holds even when the transgressor is not the one who is confronted by peril. However, it is not the case that all infringements entail the dispersal of losses. Consider those cases where the creation of the emergency was reasonably foreseeable: for example, the

${ }^{39}$ It is noteworthy that Judith Thomson does not follow in strict accordance with the received view in those cases where an agent permissibly intervenes. In cases such as trolley she is ambivalent about whether the agent is liable and in cases of rescue she suggests that the rightholder and rescuer should share the burden. Thomson, 1990, p. 100 and 1986, p. 41. 
hiker who was aware that a snow storm was expected, the individual who deliberately sets the trolley in motion in order to kill the five, the robber who threatens to kill the bank teller if she does not hand over the money, the individual who is injured when the target of his aggression responds in self-defense, and so on. In such cases the agent's transgression remains permissible, but the burden is borne by the individual who foreseeably created the predicament.

\section{CONCLUSION}

The received view contends that those individuals who permissibly transgress in response to an emergency must bear any losses that are (foreseeably) caused as a result. The existing responses to that line of argument in the literature have been primarily concerned with challenging one or more of its basic premises - namely, moral residualism, agent causation and first-order morality. Advocates of the erasure view, for example, argue that permissibility extinguishes the moral force of rights and, therefore, that shifting the burden to the agent cannot be justified on the grounds that she transgressed a right. Others may reject the causality condition because it is insensitive to luck in the way things turn out. Still others may argue that the inclusion of second-order considerations is not incompatible with the demand that we take adequate account of the victim's rights. Here, however, I have argued that the permissible transgressor is not liable even if we accept the basic premises that underpin the received view. In the first place those premises are sufficiently accommodated by a non-pecuniary duty such as a formal apology or expression of regret. In the second place, I have argued that agent's should not bear the burden created by their responses to an unforeseeable emergency because that outcome was not adequately avoidable and because of the joint causation of the predicament. A significant implication of this line of argument is that the answer to the question of what remedy the permissible transgressor owes the rightholder does not provide us with an answer to the question of who should bear the burden. This, I readily concede, represents a departure from the idea central to tort law that the 
agent must absorb those losses that are (foreseeably) caused by her wrongdoing. If the arguments presented here stand up to scrutiny, then I contend there is good reason to treat permissible responses to emergencies as an exception to that rule.

Department of Philosophy,

Faculty of Humanities and Letters,

Bilkent University,

06800 Bilkent,

Ankara, Turkey

E-mail: wigley@bilkent.edu.tr 